\title{
A INSERÇÃO PROFISSIONAL DE LICENCIADOS E MESTRES Efeitos paradoxais da feminização do ensino superior em tempos de incerteza
}

\author{
Mariana Gaio Alves \\ UIDEF, IE UL, Lisboa, Portugal \\ César Morais \\ CICS.NOVA, FCSH-UNL, Lisboa, Portugal
}

\begin{abstract}
Resumo A sobrerrepresentação feminina entre alunos do ensino superior com melhores resultados escolares e em patamares académicos mais elevados coexiste com diferenças marcantes na inserção profissional de diplomados e diplomadas, geralmente em desfavor destas. Com base na análise de dados quantitativos relativos aos graduados da Universidade Nova de Lisboa entre 2010 e 2015, evidencia-se que os percursos profissionais de homens e mulheres evoluíram de forma distinta no recente cenário de incerteza laboral e económica, sendo as assimetrias particularmente marcadas entre licenciados por comparação com mestres.
\end{abstract}

Palavras-chave: ensino superior, inserção profissional, sexo.

The transition into working like of first degree and master graduates. Paradoxical effects of the feminization of higher education in times of uncertainty

Abstract Female overrepresentation among higher education students with better school outcomes and higher academic levels coexists with marked differences in the transition to work of male and female graduates, often in disfavor of female. Based on the analysis of quantitative data regarding the graduates of the Universidade Nova de Lisboa between 2010 and 2015, it is evident that the professional paths of men and women have evolved differently in the recent scenario of job and economic uncertainty, with particularly marked asymmetries among first degree graduates compared to master graduates.

Keywords: higher education, transition to work, sex.

L'insertion professionnelle des diplômés et maîtres. Effets paradoxaux de la féminisation de l'enseignement supérieur dans les temps d'incertitude

Resumé La surreprésentation des femmes parmi les étudiants de l'enseignement supérieur ayant de meilleurs résultats scolaires et des niveaux d'enseignement supérieurs coexiste avec des différences marquées dans l'insertion professionnelle des hommes et femmes diplômés, souvent en défaveur des femmes. Sur la base de l'analyse des données quantitatives concernant les diplômés de l'Universidade Nova de Lisboa entre 2010 et 2015, il est évident que les perspectives de carrière des hommes et des femmes ont évolué différemment dans le scénario récent d'incertitude économique et professionnelle, avec des asymétries particulièrement marquées chez les diplômés par rapport aux maîtres.

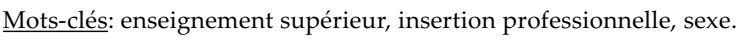

L'inserción profesional de graduados e maestros. Efectos paradójicos de la feminización de la educación superior en tiempos de incertidumbre

Resumen La sobrerrepresentación femenina entre alumnos de enseñanza superior con mejores resultados escolares y en niveles académicos más altos coexiste con diferencias marcadas en la inserción profesional de diplomados y diplomadas, generalmente en desfavor de éstas. Basado en el análisis de datos cuantitativos sobre graduados de la Universidade Nova de Lisboa entre 2010 y 2015, es evidente que los caminos profesionales de hombres y mujeres han evolucionado de manera diferente en reciente escenario de incertidumbre económica y de trabajo, con asimetrías particularmente marcadas entre licenciados por comparación con maestros.

Palabras-clave: enseñanza superior, inserción profesional, sexo. 


\section{Notas introdutórias}

É muito habitual estabelecer-se uma relação direta entre níveis dos diplomas escolares e determinadas posições que lhes corresponderiam no mercado de trabalho, numa perspetiva que é tributária da teoria do capital humano proposta por Theodore Schultz na década de 1960. De algum modo, os pressupostos desta abordagem teórica têm persistido nos discursos públicos e políticos sobre as relações entre educação, trabalho e emprego, ${ }^{1}$ sendo também utilizados pelos indivíduos para justificar as respetivas escolhas escolares e profissionais no decorrer dos seus percursos de vida (Cabrito, 1999).

A feminização do ensino superior, que se traduz no crescimento expressivo do número de mulheres que se diplomam em diferentes cursos e áreas disciplinares, não poderia deixar de ter como resultado, à luz dos pressupostos da teoria do capital humano, a respetiva inserção profissional nas condições mais favoráveis. Todavia, se a feminização do ensino superior é uma tendência transversal aos diferentes países, também se constata que os percursos de inserção profissional das mulheres são marcados por mais e maiores dificuldades do que os dos homens em várias regiões do mundo, tal como destaca a OCDE (OECD, 2016). Este desfasamento entre sucesso escolar e inserção profissional poderá ser considerado um paradoxo, face aos postulados da teoria do capital humano, mas alternativamente pode ser entendido como uma ilustração da complexidade inerente às articulações entre educação, trabalho e emprego.

A exploração de assimetrias entre mulheres e homens que obtiveram um diploma de ensino superior assume especial relevância em Portugal, pelo facto de a feminização do ensino superior constituir, no nosso país, uma tendência particularmente saliente. Segundo dados da OCDE (OECD, 2016), a percentagem de mulheres entre os licenciados e entre os mestres em Portugal ( $60 \%$ em ambos os casos) é atualmente ligeiramente superior à que se verifica em média nos países da OCDE (respetivamente $58 \%$ entre licenciados e $57 \%$ entre mestres).

Compreender o modo como a variável sexo influi na inserção profissional dos diplomados é especialmente pertinente nos anos mais recentes, tendo em conta as incertezas significativas que permeiam os percursos individuais num contexto de degradação da situação no mercado de trabalho, despoletada pela crise económica mundial de 2008 e acentuada durante o período de assistência económica em Portugal, entre 2010 e 2014, a qual afetou, especialmente, os segmentos mais jovens da população, mesmo os mais escolarizados (Costa e Caldas, 2013). Em 2015, tanto em Portugal como no conjunto da União Europeia, eram já visíveis melhorias consistentes nos indicadores macroeconómicos e do emprego, ainda que estes últimos permanecessem aquém dos registados antes do dealbar da crise

1 Neste texto, utilizamos as designações trabalho e emprego para sublinhar, partilhando da perspetiva de Doray e Maroy (1995), que as questões da relação educação-emprego se referem, principalmente, a dificuldades de acesso ao emprego e ao desemprego, enquanto a ênfase nos aspetos da relação educação-trabalho significa, sobretudo, a atenção nos saberes (desenvolvidos no sistema educativo e utilizados no espaço profissional). 
económica internacional, especialmente entre a população mais jovem e menos qualificada (Comissão Europeia, 2016).

Note-se que estes ciclos económicos decorreram num cenário global de progressiva flexibilização do sistema capitalista, o que, não sendo um sinónimo de precariedade laboral, tem vindo a resultar numa precarização transversal das condições de trabalho, especialmente a nível remuneratório e de desenvolvimento profissional, mas também das relações contratuais que regulam os empregos (Casaca, 2012). Não obstante, as análises da evolução do mercado de trabalho português durante a primeira década deste século sob uma perspetiva de género (Casaca, 2012; Ferreira, 2014; Walby, 2009), revelam que as tendências transversalmente negativas dos indicadores de emprego têm sido particularmente acentuadas no caso das mulheres, surgindo estas mais penalizadas pela crise económica e pela flexibilização laboral do que os homens, quer nas quebras no acesso ao emprego, quer na perda de qualidade das condições de trabalho.

Assim sendo, neste artigo procura-se identificar assimetrias nos percursos académicos e profissionais de homens e mulheres com diplomas de ensino superior no recente contexto de incerteza das relações entre educação, trabalho e emprego, tendo por base dados quantitativos sobre os licenciados e mestres da Universidade Nova de Lisboa (NOVA) entre os anos de 2010 e 2015. Deste modo, pretende-se contribuir para o campo de investigação sobre inserção profissional de graduados que se tem vindo a desenvolver em Portugal e noutros países (Marques e Alves, 2010), evidenciando a relevância da variável sexo no conjunto de variáveis pessoais, sociais e contextuais que influenciam os percursos dos diplomados. A análise dos dados orienta-se por forma a responder a duas interrogações:

1) Quais as tendências evolutivas relativas à presença de mulheres e homens nas graduações na NOVA desde 2010?

2) Quais as tendências evolutivas relativas à situação profissional dos diplomados e diplomadas da NOVA, um ano após a conclusão do curso, desde 2010?

\section{Inserção profissional de diplomados: contornos e possíveis razões das diferenças entre percursos de mulheres e homens}

A investigação sociológica tem contribuído para destacar a multiplicidade de fatores pessoais, sociais e contextuais que condicionam as escolhas escolares, bem como os processos de transição entre a escola e mundo do trabalho (Raffe, 2014). No caso dos graduados do ensino superior em Portugal, se por um lado os seus diplomas significam condições de trabalho e de emprego mais favoráveis, por outro lado desde o início deste século que se verifica uma deterioração geral dessas condições (Alves, 2009; Alves, Morais e Chaves, 2017) e se assinala a existência de desigualdades na transição para o mercado de trabalho, que decorrem de características pessoais e sociais dos diplomados (Chaves e Morais, 2014; Alves, 2016; Monteiro, Almeida e Aracil, 2016). Neste conjunto de investigações, existem indícios de que o sexo dos graduados é uma variável relevante para compreender 
assimetrias nos percursos de inserção profissional, sendo a sua influência mediada por outras variáveis como, por exemplo, as áreas de estudos escolhidas, as experiências profissionais durante a frequência académica ou a procura de formação ao longo da vida, incluindo pós-graduações.

Com efeito, tem vindo a ser evidenciado que as mulheres diplomadas de ensino superior experienciam mais e maiores dificuldades na inserção profissional do que os seus colegas homens. Essas dificuldades são identificáveis tanto no plano da obtenção (ou não) de um emprego, quanto nas condições em que se exerce o trabalho, designadamente no que respeita à estabilidade dos vínculos contratuais, às funções e cargos desempenhados e à adequação entre formação académica e atividade profissional. Mesmo nos países nórdicos que são apontados como mais igualitários em termos de género, Vuorinen-Lampila (2014) observa que as mulheres diplomadas de ensino superior estão mais frequentemente desempregadas e em empregos menos ajustados à sua formação. Noutros termos, importa reconhecer que as dificuldades mais acentuadas de inserção profissional das mulheres são uma tendência transnacional, ainda que possam ser particularmente notórias em países da Europa mediterrânica e central por comparação com os do Leste europeu e Escandinávia (Smyth, 2003).

As dificuldades de inserção profissional mais acentuadas das mulheres são frequentemente explicadas pela sua escolha, preferencial, de áreas de estudos que dão acesso a segmentos do mercado de trabalho que tendencialmente se caracterizam por situações profissionais menos favoráveis (Vuorinen-Lampila, 2014). Observa-se, a este propósito, que as mulheres tendem a concentrar-se, por exemplo, nas artes e humanidades ou na educação, que dão acesso a empregos cujas condições são mais desvantajosas (Themelis, 2007), e que o facto de existirem mais mulheres diplomadas de ensino superior com empregos temporários, por comparação com os seus colegas homens, também se pode relacionar com os setores de atividade, predominantemente os da "educação", da "saúde e bem-estar" e dos "serviços", em que elas maioritariamente se empregam (Alves, Morais e Chaves, 2017; Torres, 2018).

Outro conjunto de explicações para as assimetrias entre mulheres e homens na inserção profissional argumenta que os desafios da conciliação entre as esferas familiar e profissional são particularmente incisivos no caso das mulheres. Este aspeto parece ser em Portugal bastante premente, pois as trabalhadoras portuguesas tendem a despender bastante mais horas do que os homens em trabalho não remunerado, geralmente na esfera doméstica e no cuidado a crianças e familiares, mesmo em agregados familiares em que algum dos membros possui uma graduação do ensino superior (Perista et al., 2016). Neste domínio, sugere-se que estas assimetrias são identificáveis logo após a graduação e tendem a acentuar-se ao longo do tempo, até porque a constituição de família própria parece afetar negativamente os percursos de inserção profissional das mulheres, mas não os dos homens (Vuorinen-Lampila, 2014). A conciliação do trabalho com a família pode ser também um elemento relevante para explicar as dificuldades acrescidas das mulheres que concluem mestrado face às que concluem licenciatura, mencionadas por Rostan e Stan (2017). Aliás, análises longitudinais dos percursos de inserção profissional 
indiciam que as primeiras experiências profissionais tendem a ter um efeito negativo sobre as perspetivas de inserção profissional das mulheres nos anos seguintes (Monteiro, Almeida e Aracil, 2016), bem como que as desvantagens das mulheres se acentuam três e cinco anos após a conclusão do curso quando comparadas com a situação vivenciada imediatamente após a obtenção do diploma (Alves, 2004).

As maiores e mais significativas dificuldades de inserção profissional das mulheres podem ainda estar relacionadas com a sua experiência profissional prévia à obtenção do diploma. Com efeito, a conciliação da frequência académica com o exercício de atividades profissionais parece ser uma opção cada vez mais habitual entre os estudantes do ensino superior em vários países europeus (Robert e Saar, 2012; Navarro-Cendejas e Planas, 2016). As razões para essa opção podem, desde logo, ser encontradas no custo elevado que o ensino superior representa para os estudantes e suas famílias num contexto de crescente desinvestimento financeiro por parte dos estados nacionais, o que significa uma opção pelo trabalho enquanto se estuda como forma de cofinanciar os estudos. Além disso, é também de notar que a precariedade crescente do mercado de trabalho nos diferentes países faz com que existam numerosas oportunidades para experiências profissionais de curto prazo e a tempo parcial, as quais podem ser particularmente apelativas para os estudantes que as conciliam com a frequência do ensino superior (Robert e Saar, 2012). Independentemente das razões que conduzem os estudantes a trabalhar durante a frequência do ensino superior, existem indícios de que este tipo de experiências profissionais são valorizadas enquanto enriquecimento do perfil pessoal que os alunos apresentarão aos empregadores após a conclusão do curso (Tomlinson, 2008).

Ora, a este propósito, existem indícios de que a opção de trabalhar enquanto se estuda no ensino superior tende a ser mais frequente entre os homens, sendo que a experiência profissional prévia em geral (independentemente da função e da área de atividade) parece ser um critério de recrutamento valorizado positivamente pelos empregadores, o que coloca os homens em vantagem face às mulheres na fase de inserção profissional (Alves, 2004). Para além das experiências de trabalho, também as atividades extracurriculares dos estudantes do ensino superior parecem ter efeitos mais positivos na inserção profissional dos homens do que na das mulheres (Monteiro, Almeida e Aracil, 2016).

A relevância das experiências profissionais durante o curso na transição para o mercado de trabalho após a obtenção do diploma é indissociável do respetivo contributo no desenvolvimento de competências e na definição de crenças e expectativas relativamente à inserção profissional. Ora, resultados de pesquisas sugerem que os homens apresentam em geral expectativas mais elevadas de sucesso e perspetivas mais otimistas sobre o seu futuro profissional, os quais são particularmente elevados quando os mesmos têm experiência prévia de trabalho durante o curso (Monteiro, Almeida e Aracil, 2016). De modo convergente, Sin, Tavares, e Amaral (2016) realçam que as mulheres licenciadas parecem ser menos otimistas do que os homens relativamente a expectativas de inserção profissional, pelo que tendem a perspetivar a continuidade dos estudos para mestrado como uma forma de proteção contra o emprego precário. 
Todavia, existem indícios de que as mulheres licenciadas tendem a acumular a participação menos intensa em formação pós-graduada com situações de inserção profissional menos favorecidas (Alves, 2016), bem como de que, mesmo quando as mulheres investem mais e com maior sucesso em educação ao longo da vida, obtêm menos recompensas profissionais (Leathwood e Francis, 2006). Assim sendo, ao contrário de Sin, Tavares e Amaral (2016), não consideramos surpreendente que a procura de mestrado após a licenciatura possa ser bastante equitativa entre homens e mulheres, ainda que estas últimas ocupem posições menos favorecidas no mercado de trabalho e tenham percursos académicos iniciais nos quais o sucesso escolar é mais significativo. Aliás, a participação em educação ao longo da vida em geral é mais expressivamente orientada por razões profissionais no caso dos homens, pois a definição do que é apropriado para os dois grupos acaba por influenciar escolhas escolares, aspirações profissionais e aprendizagens, fazendo com que os padrões de género não sejam o resultado de escolhas individuais (Leathwood e Francis, 2006).

\section{Breve nota metodológica}

Neste artigo analisam-se dados empíricos que vêm sendo recolhidos no Observatório de Inserção Profissional de Diplomados da NOVA (OBIPNOVA) e que permitem, com rigor e exatidão, retratar os percursos de inserção profissional dos licenciados e mestres das nove unidades orgânicas desta universidade. Para tal recorre-se aos resultados de um inquérito por questionário aplicado anualmente entre 2010 e 2015 aos indivíduos que se diplomaram no ano anterior ao da inquirição, por forma a privilegiar uma análise evolutiva longitudinal da inserção profissional nesse período de seis anos.

Nestes sucessivos inquéritos foram seguidos procedimentos de amostragem probabilística, constituindo-se amostras aleatórias simples para cada ano e ciclo de ensino. As taxas de resposta anuais situam-se entre os $50 \%$ e os $75 \%$, tanto entre licenciados como para mestres e, considerando um intervalo de confiança de $95 \%$, as margens de erro amostral não ultrapassam os 2,4\% em qualquer dos anos ou ciclos de estudo em análise ( $C f$. Anexo I - Universo, amostra, taxa de resposta e margem de erro amostral para as inquirições do OBIPNOVA a licenciados e mestres da NOVA entre 2010 e 2015).

A significância estatística das diferenças entre homens e mulheres nas várias variáveis e anos em análise (Cf. Anexo II - Variáveis utilizadas na análise por ano e sexo, valores absolutos), foi testada através de testes de Qui-quadrado no caso de variáveis categoriais e por recurso a testes t para amostras independentes (considerando um nível de confiança de 95\%) no que concerne a variáveis contínuas, quando se verifica a adequação dos dados aos pressupostos desses testes.

Importa, desde logo, sublinhar que esta análise não pretende ser representativa da situação profissional dos licenciados e dos mestres em Portugal. Na inexistência desses dados a nível nacional, pois as estatísticas oficiais do emprego agregam os diplomados dos vários ciclos do ensino superior numa única categoria 
e não possibilitam uma análise que tenha como referência a data de obtenção do diploma, considera-se a inserção profissional apenas dos diplomados da NOVA. Ainda que incidindo apenas sobre os diplomados de uma única universidade, é possível destrinçar variações em função do grau do diploma e monitorizar com rigor a situação dos diplomados um ano após a conclusão do respetivo curso. Em contrapartida, antecipa-se que seja expectável que o retrato assim traçado reflita uma situação particularmente favorável face ao cenário vivido pelo conjunto dos graduados em Portugal, tal como se assinala numa análise de Chaves e Morais (2014), que cotejou os destinos profissionais de jovens licenciados nesta universidade e na Universidade de Lisboa com os da globalidade dos graduados em Portugal em idades similares.

\section{Licenciados e mestres da NOVA: tendências e contornos da feminização}

A tendência para a feminização de estudantes e diplomados do ensino superior é observável na NOVA nos anos mais recentes. Com efeito, em 2015 as mulheres não só se encontram em franca maioria, quer entre licenciados (59,3\%) quer entre mestres $(58,5 \%)$, como essa vantagem percentual aumenta face a 2010, ainda que de forma mais acentuada nas licenciaturas do que nos mestrados, respetivamente, 8,4 pontos percentuais (p.p.) e 1,5 p.p. Este diferencial evolutivo é convergente com os estudos já mencionados, que referem que a participação de mulheres e homens tende a ser mais equitativa em formação pós-graduada por comparação com a formação graduada (Alves, 2016; Sin, Tavares e Amaral, 2016).

No que respeita às idades destes diplomados um ano após a conclusão do curso, as assimetrias entre mulheres e homens são bastante ligeiras ainda que globalmente apontem para que as diplomadas sejam um pouco mais novas entre licenciados e um pouco mais velhas entre mestres. ${ }^{2}$ Assinale-se também que entre 2010 e 2015 se verifica uma discreta redução da média etária dos diplomados que, no primeiro desses anos, ronda os 25 anos entre os licenciados e 30 anos no caso dos mestres, enquanto em 2015 se situa, respetivamente, nos 24 e 28 anos.

Quanto às áreas de educação e formação em que se diplomaram, sobressaem notórias diferenças entre mulheres e homens, que pouco evoluem durante os seis anos em análise e que maioritariamente se revestem de significado estatístico. ${ }^{3} \mathrm{Nas}$ licenciaturas, as mulheres surgem polarizadas pelas áreas das "artes e humanidades" e das "ciências sociais, comércio e direito", esta última também frequente entre os homens a par com as "ciências, matemática e informática". Este cenário é extensível aos mestrados, acrescendo neste caso a sobrerrepresentação das mulheres em "educação" e "saúde e proteção social", e dos homens em "engenharia, indústrias transformadoras e construção".

2 De acordo com o teste $\mathrm{t}$, em nenhum dos anos as diferenças entre as idades médias de licenciados e licenciadas são estatisticamente significativas. No caso dos mestres, este teste assinala diferenças estatisticamente significativas na média etária de acordo com o sexo em 2010 ( $\mathrm{t}(1028)=$ $2,25, p=0,025)$ e 2011 ( $(\mathrm{t}(942)=2,27, p=0,024)$. 


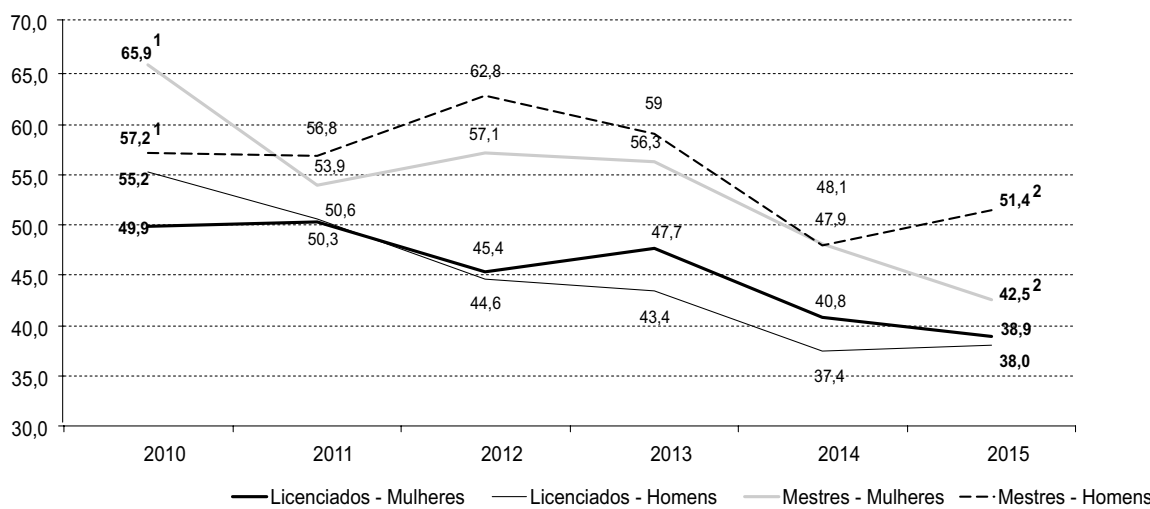

Figura 1 Trabalhadores-estudantes durante o curso entre licenciados e mestres da NOVA por sexo (\%) $1 \chi^{2}(1)=8,3, p=0,004 ; 2 \chi^{2}(1)=6,6, p=0,01$.

Fonte: OBIPNOVA.

A observação da figura 1 revela, globalmente, um decréscimo da percentagem de trabalhadores-estudantes, tanto nas licenciaturas como nos mestrados, que importa salientar, dado que outras investigações têm indicado que é cada vez mais frequente a conciliação de estudos com trabalho (Navarro-Cendejas e Planas, 2016; Robert e Saar, 2012). Esta situação poderá, pelo menos em parte, estar relacionada com o contexto de crise económica e consequente contração do emprego que vigorou durante a maioria dos anos em análise.

No plano das assimetrias observa-se que a percentagem de mulheres entre os trabalhadores-estudantes a nível de mestrado tem vindo a diminuir desde 2010 de modo particularmente acentuado. Nas licenciaturas, constata-se que em 2010 existiam mais homens do que mulheres como trabalhadores-estudantes, mas os dois grupos tendem a estar quase equiparados (como um ligeira superioridade percentual das mulheres) em 2015. Assim, entre 2010 e 2015, as diferenças entre os dois grupos na conciliação do trabalho com o estudo parecem ter-se acentuado entre os mestres e diminuído entre os licenciados, assumindo significado estatístico a associação entre sexo e trabalhadores-estudantes no caso dos mestres nos anos de 2010 e 2015. Assim sendo, se admitirmos, tal como sugerem alguns estudos (Alves, 2004; Monteiro, Almeida e Aracil, 2016), que a experiência profissional prévia à obtenção do diploma

3 O teste do Qui-quadrado assinala uma associação estatisticamente significativa entre a área de educação e formação dos licenciados e o seu sexo em todos os anos: $2010\left(\chi^{2}(4)=36,5, p<0,001\right)$; $2011\left(\chi^{2}(3)=27,9, p<0,001\right) ; 2012\left(\chi^{2}(3)=20,7, p<0,001\right) ; 2013\left(\chi^{2}(2)=33,7, p<0,001\right) ; 2014\left(\chi^{2}(2)=\right.$ $20,9, p<0,001)$; e $2015\left(\chi^{2}(2)=16,7, p<0,001\right)$. O mesmo sucede com os mestres: $2010\left(\chi^{2}(5)=39,6\right.$, $p<0,001) ; 2011\left(\chi^{2}(6)=86,4, p<0,001\right) ; 2012\left(\chi^{2}(6)=63,0, p<0,001\right) ; 2013\left(\chi^{2}(6)=78,0, p<0,001\right)$; $2014\left(\chi^{2}(6)=65,1, p<0,001\right)$; e $2015\left(\chi^{2}(6)=47,5, p<0,001\right)-$ nos anos de 2012 e 2013 os resultados deste teste foram confirmados através de uma simulação Monte Carlo $(p<0,001$ em ambos) uma vez que existem células com valor esperado inferior a 1. 
facilita a transição posterior para o mercado de trabalho, poderemos estar a assistir nos anos mais recentes a um acentuar das desvantagens das mulheres que concluem o grau de mestre.

\section{Licenciados e mestres da NOVA: situação profissional de mulheres e homens}

Para aferir a situação profissional dos diplomados da NOVA um ano após a graduação, recorremos às definições estabelecidas pelo Labour Force Survey e adotadas no conjunto da União Europeia para os classificar enquanto empregados, desempregados ou (economicamente) inativos, calculando depois as respetivas taxas.

Globalmente, a evolução da taxa de emprego compreende duas fases distintas: até 2012, período em que a taxa de emprego recua ininterruptamente e de forma geral; e depois de 2012, quando se verifica uma recuperação transversal dos níveis de emprego, ainda que estes permaneçam aquém dos registados em 2010. Trata-se de uma evolução negativa que reflete o período de crise económica em Portugal mas que, como seria expectável, se revela mais favorável do que a registada para o conjunto dos graduados portugueses do ensino superior com idades similares, para os quais a recuperação da taxa de emprego só decorre a partir de 2014 (Alves, Morais e Chaves, 2017) a par com os primeiros indícios de retoma macroeconómica nacional (figura 2).

O valor anual da taxa de emprego entre licenciados é sempre inferior no caso das mulheres e essa diferença aumenta de 6,7 p.p. em 2010 para 7,7 p.p. em 2015, pois mesmo que a quebra dos níveis de emprego entre os homens seja mais acelerada até 2012 a sua recuperação a partir desse ano seja também mais evidente. No que concerne aos mestres, ainda que se verifique uma menor distância entre homens e mulheres, o diferencial em desfavor destas últimas também tende a aumentar entre 2010 (0,8 p.p.) e 2015 (3,7 p.p.) pois, tal como sucede entre licenciados, a taxa de emprego masculina decresce mais rapidamente até 2012 mas recupera de forma mais célere nos anos seguintes. A maior penalização no emprego masculino até 2012, visível tanto entre os licenciados como entre os mestres da NOVA, deverá resultar principalmente do desenrolar setorial da crise do emprego, uma vez que os primeiros setores económicos afetados foram justamente os mais masculinizados, como no caso da construção e das obras públicas (Ferreira, 2014), um destino profissional particularmente frequente entre os homens com mestrado da NOVA por via da sua maior representação na área de estudos da "engenharia, indústrias transformadoras e construção".

Destaque-se, ainda, a clara clivagem entre ciclos de ensino, pois a taxa de emprego entre mestres, além de menos permeável a oscilações, supera largamente a dos licenciados. Esta distinção entre ciclos de ensino poderá estar associada à crescente procura de mestrados entre os licenciados em Portugal (Cardoso et al., 2012) que terá sido reforçada com a implementação do processo de Bolonha no país no ano letivo de 2006/07. Para além disso, é relevante notar que os trabalhadores-estudantes são mais frequentes ao nível do mestrado, pelo que a inserção profissional após a obtenção do diploma pode enquadrar-se numa lógica de continuidade da sua situação profissional anterior. 


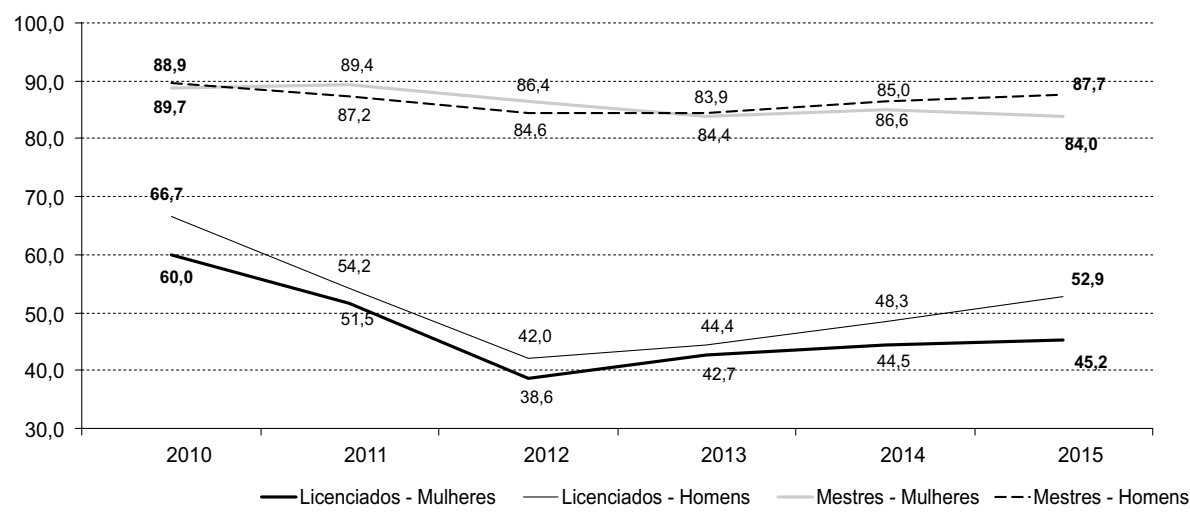

Figura 2 Taxa de emprego entre 2010 e 2015 para licenciados e mestres da NOVA por sexo (\%) Fonte: OBIPNOVA.

A redução significativa da taxa de emprego entre os licenciados da NOVA, ao invés de resultar num aumento similar do desemprego, motivou antes o crescimento das situações de inatividade económica, maioritariamente relacionadas com o prosseguimento de estudos académicos. Assim, perante maiores dificuldades em obter um emprego, a maioria destes licenciados procurou refúgio no sistema de ensino prolongando a sua escolaridade, sendo esta uma opção que parece tornar-se cada vez mais frequente entre os graduados do ensino superior em Portugal (Alves, Alves e Chaves, 2012). Já entre os mestres, quer as situações de desemprego, quer as de inatividade afiguram-se bastante mais raras (figura 3).

O progressivo avolumar das situações de inatividade entre 2010 e 2015 torna-se mais evidente entre as mulheres licenciadas, justamente as mais afetadas pela contração no emprego. Este efeito de "refúgio" proporcionado pelo ensino superior pode também contribuir para a já assinalada e notória feminização dos graduados na NOVA durante estes anos. No caso dos homens, o regresso ou a permanência na esfera académica após a conclusão da licenciatura aumenta em paralelo com o rápido crescimento da inatividade até 2012, mas recua progressivamente a partir desse ano, ou seja, uma evolução simétrica à dos seus níveis de emprego. Entre mestres as assimetrias são bastante discretas mas idênticas, ou seja, na maioria dos anos em análise a taxa de inatividade é maior entre as mulheres e, ainda que com oscilações, esse diferencial aumenta ao longo do período em análise.

Convém sumariar que as diplomadas da NOVA surgem assim duplamente penalizadas. Primeiramente porque possuem níveis de emprego inferiores, o que redunda numa maior incidência de desemprego e inatividade, ainda que esta última situação geralmente se alie ao prosseguimento de estudos académicos; e, em segundo lugar, porque a recuperação após um período transversal de contração do emprego é menos célere entre as mulheres, o que faz aumentar o diferencial em seu desfavor. Esta situação surge mais notória entre licenciados, uma vez que a inserção profissional dos 


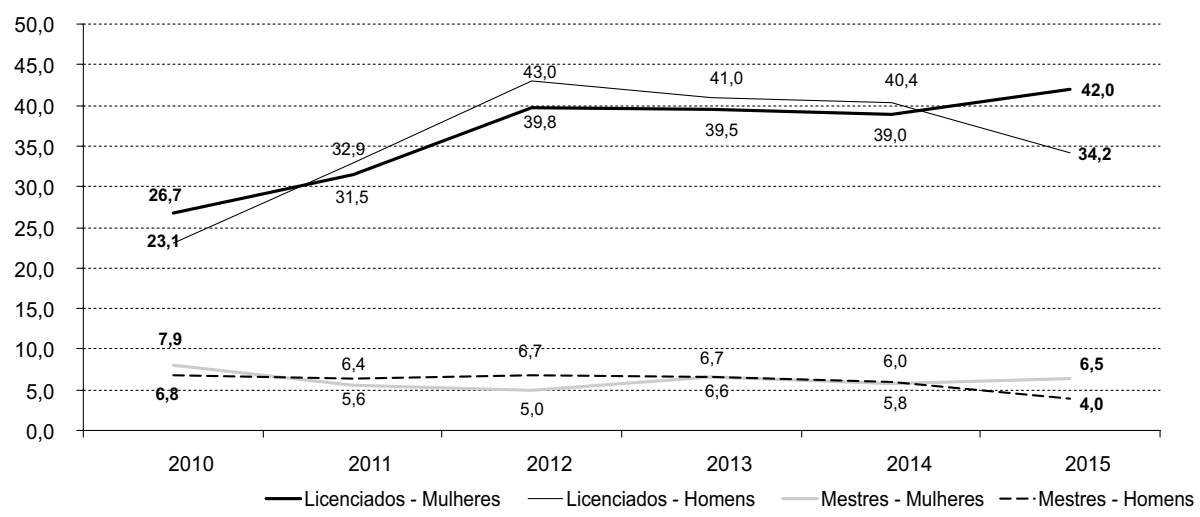

Figura 3 Taxa de inatividade entre 2010 e 2015 para licenciados e mestres da NOVA por sexo (\%) Fonte: OBIPNOVA.

mestres se afigura mais equitativa entre mulheres e homens, sendo também mais estável e com níveis de emprego mais elevados.

Os indicadores que abordaremos de seguida concernem apenas aos diplomados empregados e permitem observar a evolução de algumas características dos seus empregos. O trabalho temporário, onde se incluem os empregos com vínculos contratuais de duração limitada e as posições laborais independentes não reguladas por qualquer tipo de contrato de trabalho, assume uma expressão significativa entre os diplomados em análise, englobando perto de dois terços do total de licenciados empregados e cerca de metade dos mestres entre 2010 e 2015 (figura 4).

Tanto na incidência como nas oscilações do trabalho temporário, são as trabalhadoras que surgem numa posição de desvantagem. No que respeita aos licenciados, com exceção de 2013, o trabalho temporário é mais frequente entre as mulheres e, ainda que com flutuações, a distância percentual entre homens e mulheres em desfavor destas últimas aumenta entre 2010 (4,5 p.p.) e 2015 (8,4 p.p.). Também no caso dos mestres, excetuando o ano de 2013, a incidência de empregos temporários é maior entre as mulheres e o diferencial entre homens e mulheres oscila entre 1 p.p.e 5 p.p. ao longo dos seis anos em análise.

Não obstante a tendência transversal para a precarização dos vínculos contratuais no mercado de trabalho português, antecipa-se que a elevada incidência do trabalho temporário entre os diplomados em análise não será alheia ao facto de estes terem terminado os seus cursos cerca de um ano antes do momento a que estes dados se referem. Ou seja, os inquiridos encontram-se num fase inicial do percurso de inserção profissional que se afigura especialmente permeável a situações contratuais temporárias, como os estágios profissionais ou outros períodos probatórios, mesmo aqueles requeridos por ordens profissionais para o exercício de profissões específicas como a advocacia ou a medicina. Acresce que os anos sob observação coincidem quer com a implementação de um conjunto de reformas laborais destinadas a flexibilizar o mercado de trabalho agilizando a contratação 


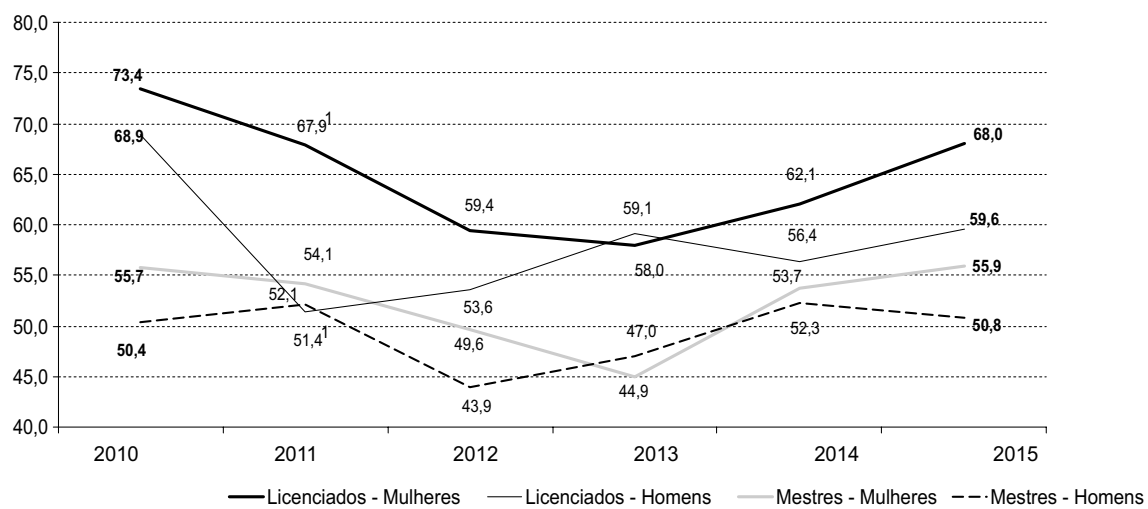

Figura 4 Trabalho temporário entre 2010 e 2015 para licenciados e mestres da NOVA por sexo (\%) $1 \chi^{2}(1)=8,3, p=0,004$

Fonte: OBIPNOVA.

temporária (Costa e Caldas, 2013), quer com a persecução de várias políticas ativas de emprego para recém-graduados direcionadas sobretudo para promoção de empregos de duração limitada (Valadas, 2013). Por outro lado, note-se que a parcela de diplomados com um emprego temporário diminui até 2012 e, ainda que com oscilações, aumenta a partir desse ano. Esta evolução espelha a traçada antes para o emprego, revelando assim que para estes diplomados a contração do emprego até 2012 foi maioritariamente suportada pelo despedimento de trabalhadores temporários, tal como o posterior período de expansão do emprego se alicerça sobretudo em contratação temporária.

Procuramos também avaliar a adequação entre as atividades profissionais realizadas pelos diplomados e o seu nível de instrução, sabendo que a desadequação traduz uma situação de sobrequalificação (Ramos, Parente e Santos, 2014). Assume-se o mesmo critério das estatísticas europeias divulgadas pelo Eurostat (Rademacher e Leitner, 2009), que considera as três primeiras categorias da International Standard Classification of Occupations (ISCO) - equiparáveis aos três primeiros grupos profissionais da Classificação Portuguesa das Profissões ${ }^{4}$ - ajustadas aos níveis de instrução 5 a 8 da ISCO, ou seja, a todos os graduados do ensino superior.

A figura 5 deixa de imediato patentes distintas realidades para licenciados e mestres, estes últimos com níveis de adequação profissional massivos que, apesar de recuarem cerca de 5 p.p. entre 2010 e 2015, ultrapassam sempre os $90 \%$ e revelam uma elevada paridade entre mulheres e homens. No caso dos licenciados a sobrequalificação também aumenta neste período, sendo as assimetrias assinaláveis e crescentes sempre em prejuízo das mulheres, bem como significativas do

4 Nomeadamente, (1) "representantes do poder legislativo e de órgãos executivos, dirigentes, diretores e gestores executivos", (2) "especialistas das atividades intelectuais e científicas" e (3) "técnicos e profissionais de nível intermédio". 


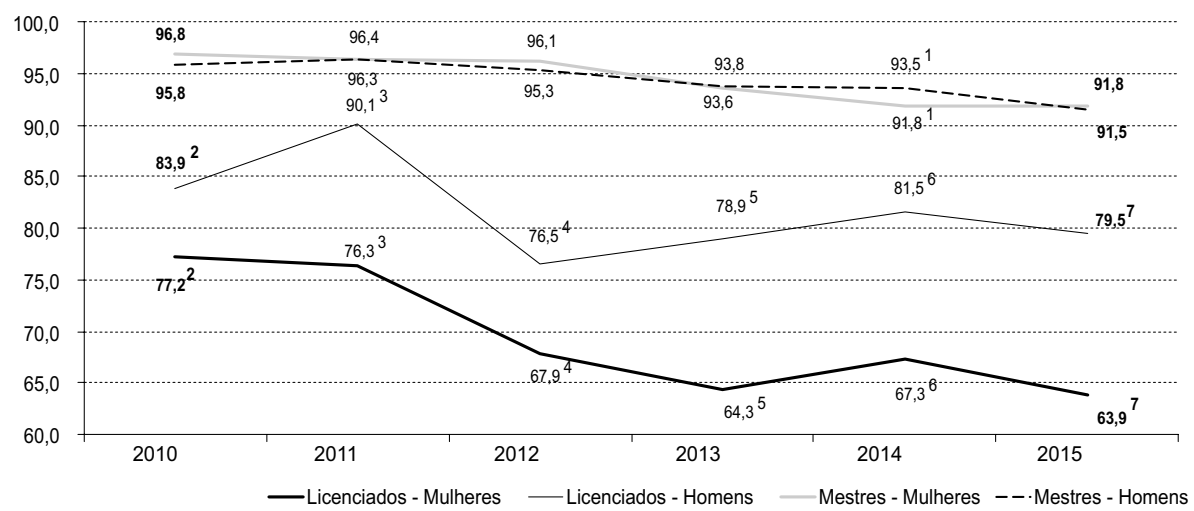

Figura 5 Adequação da profissão ao nível de instrução entre 2010 e 2015 para licenciados e mestres da NOVA por sexo (\%)

$1 \chi^{2}(1)=4,8, p=0,029 ; 2 \chi^{2}(1)=6,2, p=0,013 ; 3 \chi^{2}(1)=13, p<0,001 ; 4 \chi^{2}(1)=4,1, p=0,044$;

$5 \chi^{2}(1)=8,3, p=0,004 ; 6 \chi^{2}(1)=13,1, p<0,001 ; 7 \chi^{2}(1)=10,8, p=0,001$

Fonte: OBIPNOVA.

ponto de vista estatístico. Com efeito, na maioria dos anos em análise a parcela de homens com licenciatura que possui profissões ajustadas ao seu nível de estudos ronda ou supera os $80 \%$ e reduz-se apenas 4,4 p.p. entre 2010 e 2015 , enquanto no caso feminino o ajustamento profissional nunca supera os $77 \%$, ficando na maioria dos anos aquém dos $70 \%$ e sofrendo uma quebra de cerca de 13 p.p. ao longo desse período.

Este aumento continuado das situações de sobrequalificação, especialmente visível no caso das licenciadas, encontra-se em grande medida associado às crescentes dificuldades para obter um emprego que, como assinalámos antes, são também particularmente vincadas entre as licenciadas. Perante a impossibilidade de obter um emprego desejado ou, tampouco, adequado à sua área específica de formação, os graduados do ensino superior aceitam por vezes ocupar posições profissionais que não se ajustam sequer ao seu nível de instrução. Trata-se de empregos "de espera" (Alves, 2009) ou "de oportunidade" (Gonçalves, 2013), que implicam custos económicos elevados a nível individual (McGuinness, 2006), assim como potenciam a quebra de expectativas face ao retorno do investimento em ensino e a insatisfação no emprego (Allen e Velden, 2007).

Uma das faces mais visíveis das "barreiras invisíveis" que se erguem nas organizações e que dificultam a ascensão das mulheres na sua hierarquia (Acker, 2009) remete para o menor número de mulheres em cargos de chefia ou direção. No caso dos diplomados da NOVA este tipo de desigualdade no trabalho é flagrante, uma vez que a parcela de mulheres que declara que nas suas atividades laborais regulares supervisiona, ou dirige, o trabalho de outros, é bastante mais exígua do que a dos homens, tanto entre os licenciados como entre os mestres (figura 6). 


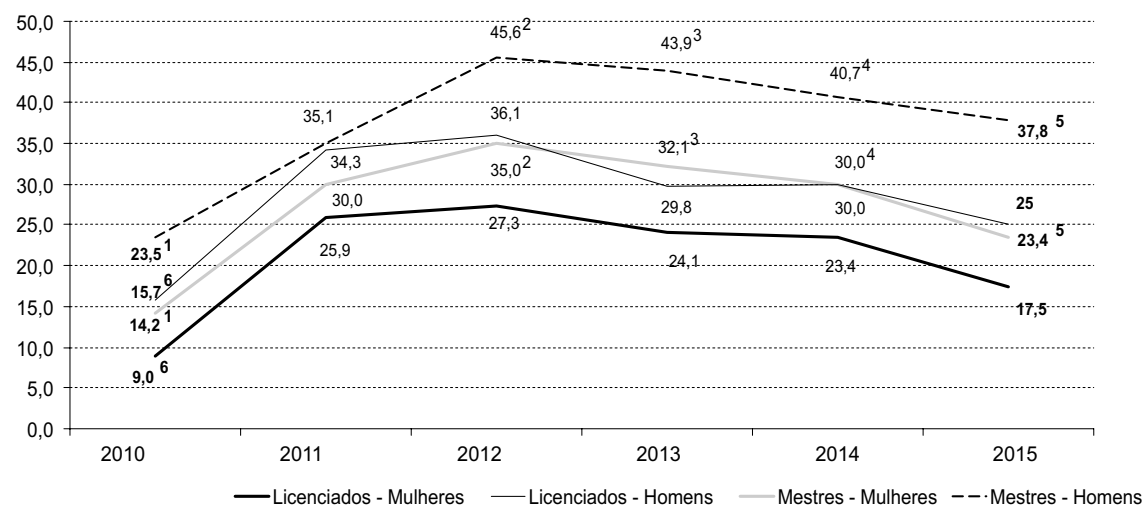

Figura 6 Cargos de chefia entre 2010 e 2015 para licenciados e mestres da NOVA por sexo (\%) $1 \chi_{2}^{2}(1)=13,1, p<0,001 ; 2 \chi_{2}^{2}(1)=11,8, p=0,001 ; 3 \chi^{2}(1)=14,6, p<0,001 ; 4 \chi^{2}(1)=13,1, p<0,001$; $5 \chi^{2}(1)=17,2, p<0,001 ; 6 \chi^{2}(1)=5,9, p=0,015$

Fonte: OBIPNOVA.

A variável sexo parece assim sobrepor-se ao grau académico para explicar a ocupação de cargos de chefia, pois em cinco dos seis anos em análise existem mais homens do que mulheres nestas posições, independentemente do seu nível de estudos. Uma assimetria que se reforça entre 2010 e 2015 aumentando de, respetivamente, 6,7 p.p. para 7,5 p.p. no caso dos licenciados e de 9,3 p.p. para 14,4 p.p. no dos mestres. Como seria expectável, os mestres surgem mais aliados a posições de chefia, porém é também entre estes que as desigualdades entre homens e mulheres se extremam e assumem contornos estatisticamente significativos.

O rendimento salarial assume-se como palco de notáveis diferenças entre sexos no mercado de trabalho português (Torres, 2009). No contexto europeu, Portugal afirma-se como um dos países onde a disparidade salarial global entre homens e mulheres é mais elevada - apenas superada por seis de um total de 28 países em 2015 - e onde mais tem crescido nos últimos anos (Eurostat, 2016). A evolução das remunerações mensais médias líquidas no emprego principal dos diplomados da NOVA entre 2010 e 2015, denota o mesmo tipo de diferenças entre mulheres e homens que encontramos para a população portuguesa em geral. ${ }^{5}$ Com efeito, durante esses seis anos as mulheres auferiram, em média, cerca de $20 \%$ menos do que homens ao nível da

5 Ao se perscrutarem diferenças salariais entre homens e mulheres, o indicador base utilizado e a forma de aferir diferenciais entre sexos assumem grande importância, pois pequenas diferenças a este nível podem redundar em resultados muito distintos. De acordo com Ferreira (2010), não existindo um indicador por excelência para aferir as disparidades salariais, qualquer comparação "tem que garantir, em primeiro lugar, a harmonização dos termos a contrastar" (p. 143). Desta forma os valores aqui escrutinados referem-se ao rendimento líquido mensal em euros com a principal atividade económica dos graduados da NOVA no período que nos serve de referência, não considerando, portanto, outros rendimentos que estes eventualmente auferissem. As diferenças nestes rendimentos entre graduados e graduadas serão expressas em percentagem, tomando como referência o valor em euros mais elevado nesse conjunto; o mesmo exercício será aplicado quando se confrontam licenciados e mestres. 


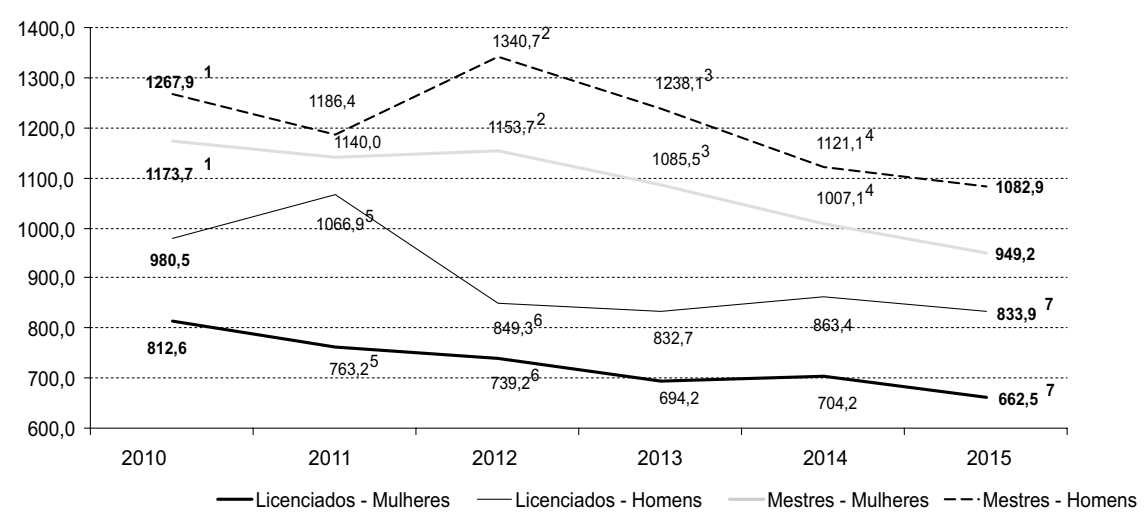

Figura 7 Remuneração mensal líquida média entre 2010 e 2015 para licenciados e mestres da NOVA por sexo (euros).

$1 \mathrm{t}(740)=4,2, p=0,018 ; 2 \mathrm{t}(658)=30,5, p<0,001,3 \mathrm{t}(732)=19,3, p<0,001 ; 4 \mathrm{t}(448)=14,1, p<0,001$; $5 \mathrm{t}(259)=21,1, p<0,001 ; 6 \mathrm{t}(289)=3,3, p=0,022 ; 7 \mathrm{t}(262)=7,7, p<0,001$

Fonte: OBIPNOVA

licenciatura e cerca de $10 \%$ menos ao nível do mestrado; este diferencial, com oscilações, tende a crescer ao longo dos anos, pois os rendimentos recuam cerca de $17 \%$ entre os homens e mais de $23 \%$ entre as mulheres, tanto ao nível da licenciatura como do mestrado (figura 7).

Além das evidentes e crescentes disparidades salariais entre homens e mulheres, sobressaem os distintos níveis remuneratórios de licenciados e mestres - os últimos auferem, em média, cerca de $28 \%$ mais do que os primeiros - e também a redução transversal dos rendimentos salariais entre 2010 e 2015 - que recuam cerca de $18 \%$ neste período, quer entre licenciados quer entre mestres. Note-se que essa redução das remunerações é quase contínua, apesar da recuperação quantitativa dos níveis de emprego destes mesmos graduados a partir de 2012 e da retoma macroeconómica em Portugal a partir de 2014, o que indicia que a pauperização dos rendimentos salariais entre os diplomados da NOVA não resulta apenas de contrações no emprego ou de ciclos económicos negativos. Desde logo, devemos considerar que esta análise recai sobre valores líquidos, ou seja, são afetados negativamente pelo aumento dos impostos e de outras contribuições sociais implementadas durante o período de assistência económica em Portugal entre 2011 e 2014 e que, na sua maioria, ainda vigoravam em 2015. Acresce que a progressiva contração do setor público de emprego nos anos em análise, tanto no volume de (novas) contratações, como nas reduções salariais ou congelamentos de carreiras, também contribuem para a redução global das remunerações, uma vez que este setor acolhe parte significativa dos diplomados da NOVA. ${ }^{6}$ A diminuição

6 Em 2010 a parcela de diplomados da NOVA empregados no setor público, quer em “Organismos da administração pública", quer em "empresas públicas ou mistas", supera os $33 \%$ entre os licenciados e os $58 \%$ no caso dos mestres, enquanto em 2015 o setor público não engloba mais que $18 \%$ dos licenciados e $40 \%$ dos mestres. 
dos níveis salariais destes diplomados associa-se ainda com a redução da qualidade dos seus empregos que vimos a assinalar, patente quer nos índices crescentes de trabalho temporário e de sobrequalificação, quer no progressivo afastamento de cargos de chefia. Ainda que este recuo qualitativo seja partilhado por licenciados e mestres, foram as mulheres que mais o sentiram e, portanto, é também entre elas que os rendimentos do trabalho mais recuam, o que resulta num progressivo aumento das assimetrias salariais entre homens e mulheres.

A título experimental, os vários anos sob escrutínio foram reunidos num único conjunto e cada uma das dimensões da situação profissional dos diplomados da NOVA que analisámos antes, nomeadamente situação perante a atividade, trabalho temporário, adequação profissional, cargos de chefia e rendimento mensal, foi tomada enquanto variável dependente numa regressão categorial (via optimal scaling) que incluiu como variáveis independentes o sexo, a área de formação académica e ser trabalhador-estudante durante o curso. Estas várias regressões permitiram confirmar a importância das três variáveis independentes na explicação do comportamento das variáveis dependentes, tanto para os licenciados como para os mestres. Com efeito, apenas não se revelou estatisticamente significativa a influência do sexo na situação perante a atividade dos mestres e de ser trabalhador-estudante durante o curso na adequação profissional dos mestres.

Constatou-se depois que, se a variável sexo não fosse introduzida nessas regressões, deixando de se controlar a sua influência sobre as restantes, aumentava de forma assinalável o nível de importância (coeficiente de Pratt) da área de formação académica e de ser trabalhador-estudante durante o curso, o que constitui forte indício de que a variável sexo é um elemento mediador dos efeitos daquelas duas variáveis na inserção profissional dos licenciados e mestres da NOVA. Ou seja, mesmo em áreas de formação idênticas, ou em situações de trabalho durante o curso semelhantes, os destinos profissionais de homens e mulheres tendem a ser distintos e, conforme constatámos antes, mais desfavoráveis para as trabalhadoras.

\section{Notas conclusivas}

Neste artigo, procura-se contribuir para o campo de investigação sobre inserção profissional de diplomados do ensino superior numa dupla perspetiva. Por um lado, identificam-se assimetrias entre os percursos académicos e profissionais de homens e mulheres com diplomas de ensino superior num contexto de incerteza nas relações entre educação, trabalho e emprego, tendo por base dados recolhidos através de inquéritos por questionário aos licenciados e mestres da NOVA entre 2010 e 2015. Por outro lado, ainda que estes resultados empíricos se circunscrevam aos licenciados e mestres de uma única universidade, as assimetrias observadas evidenciam a relevância da variável sexo, sua articulação com outras variáveis e respetiva influência nos percursos de inserção profissional dos diplomados.

No plano da identificação de assimetrias, sublinhe-se que a tendência geral para a feminização dos estudantes e diplomados de ensino superior é, tal como seria expectável, também observável no caso da NOVA nos anos mais recentes, dado 
o progressivo aumento percentual das mulheres entre os mestres, mas sobretudo, de forma especialmente acentuada, entre os licenciados. Neste sentido, a tendência para a feminização dos estudantes de ensino superior parece ser particularmente expressiva nas idades mais jovens e nas etapas iniciais de formação académica.

Não obstante, a feminização do ensino superior continua a coexistir com situações de inserção profissional que revelam assimetrias em desfavor das mulheres, as quais tenderam até a agravar-se recentemente. Na verdade, é notório que as diplomadas da NOVA protagonizam mais frequentemente situações de desemprego e de inatividade, e que há mais mulheres do que homens a exercer atividades profissionais para as quais poderão estar sobrequalificadas, em situações de emprego temporário, auferindo rendimento salariais em média mais baixos e raramente ocupando cargos de chefia. Concomitantemente, observa-se que todos estes indicadores são mais favoráveis entre mestres do que entre licenciados, bem como que algumas assimetrias entre mulheres e homens são bastante mais acentuadas entre os licenciados, designadamente é notória a maior paridade dos dois sexos entre os mestres no que respeita a taxas de emprego e inatividade e à sobrequalificação. Assim sendo, observa-se que tendem a ser as mulheres em idades mais jovens e com o grau de licenciatura que vivenciam situações de inserção profissional globalmente menos favoráveis.

Adicionalmente, no contexto de contração quantitativa e qualitativa e de flexibilização do emprego que caracteriza os seis anos em análise, as diferenças entre estes diplomados no mercado de trabalho parecem ter aumentado. Este resultado sugere que os tempos de incerteza que se têm vivido tendem a ser mais penalizadores para a inserção profissional das mulheres diplomadas, por comparação com as situações vivenciadas pelos homens. Não obstante o cariz igualitário da legislação laboral portuguesa e a constatação de que em Portugal têm diminuído as disparidades de emprego entre homens e mulheres com idades entre os 15 e os 65 anos (Torres, 2018), as assimetrias na inserção profissional de diplomados e diplomadas da NOVA sobressaem apenas um ano após a sua graduação, sugerindo que importa considerar especificamente o caso dos recém-graduados em prol da igualdade entre os dois grupos em análise. Nomeadamente porque estes dados sugerem o forte enraizamento de culturas organizacionais genderizadas no contexto laboral português como barreira à concretização de uma legislação pró-igualdade (Santos, 2010), uma vez que a sua aplicação tende a ignorar as atuais práticas e representações sociais que permeiam o mercado de trabalho em Portugal.

Destaque-se, ainda, que nos dados da NOVA se constata uma associação, com claro significado estatístico, entre as variáveis sexo e área disciplinar de estudos. Entre licenciados, as mulheres surgem polarizadas pelas áreas das "artes e humanidades" e das "ciências sociais, comércio e direito", enquanto entre mestres acresce a sua sobrerepresentação em "educação" e "saúde e proteção social". O facto de alguns dos cursos nestas áreas conduzirem a setores do mercado nos quais as condições de trabalho e emprego são geralmente menos vantajosas poderá, em parte, explicar que o maior investimento feminino no prolongamento do percurso escolar não se traduza, paradoxalmente, em situações de inserção profissional mais favorecidas para elas. Esta é uma hipótese de trabalho que julgamos merecer esclarecimento, contudo carece de uma análise ao percurso profissional de graduados e 
graduadas detalhada por curso e ciclo de estudos que os dados sob escrutínio não permitem realizar proficuamente.

Também se evidenciou um decréscimo geral da conciliação entre trabalho e estudo, que surge porém particularmente visível entre as mulheres nos cursos de mestrado e nos anos mais recentes. Por um lado, este resultado contraria a ideia de que esta conciliação seria cada vez mais frequente, sobretudo em tempos de incerteza e crise económica. Por outro lado, o facto de cada vez menos mulheres trabalharem enquanto estudam pode significar que acumulam mais desvantagens para enfrentar a sua inserção profissional após a obtenção do grau. Neste âmbito, importa explorar futuramente que razões podem explicar a diminuição de trabalhadores-estudantes em geral, e das mulheres que optam por essa conciliação entre trabalho e estudo em particular, bem como os possíveis efeitos destas opções na inserção profissional após a conclusão do curso.

Globalmente, a análise apresentada neste artigo corrobora, de algum modo, os postulados da teoria do capital humano, no sentido em que é observável que os mestres não só protagonizam situações de inserção profissional mais favoráveis do que os licenciados, como também menos assimétricas entre mulheres e homens. Estas marcadas diferenças entre ciclos de ensino aconselham a que, em futuras análises à inserção profissional de graduados do ensino superior, se considerem os diferentes graus académicos. Contudo, simultaneamente, a análise desenvolvida questiona esses postulados, pois evidencia que as situações de inserção profissional estão associadas a assimetrias entre mulheres e homens que, especialmente entre licenciados mas também entre mestres, significam desvantagens para as mulheres.

Noutros termos, o desfasamento entre o sucesso escolar das mulheres e a respetiva inserção profissional, que fica corroborado na análise desenvolvida neste artigo, pode ser considerado um paradoxo face aos postulados da teoria do capital humano, ainda que esta teoria constitua uma referência teórica inaugural e incontornável no campo de investigação das relações entre educação, trabalho e emprego. De facto, sugere-se a necessidade de, alternativamente, privilegiar perspetivas analíticas e conceptuais que permitam considerar a heterogeneidade de variáveis intervenientes na inserção profissional, a qual não pode ser entendida como o resultado de opções individuais que têm por base uma racionalidade económica, mas sim como um processo multidimensional que envolve um conjunto de atores e fatores diversificados.

Neste âmbito, a variável sexo surge particularmente relevante, ainda que estreitamente associada a outras, de entre as quais destacamos a idade e a área disciplinar de estudos, pela sua notória influência nos percursos académicos e profissionais dos indivíduos. Igualmente se evidencia, na análise desenvolvida, que estas inter-relações de variáveis são afetadas pelo contexto económico e do mercado de trabalho, sendo os efeitos paradoxais da feminização do ensino superior na inserção profissional particularmente visíveis nos anos mais recentes. É que as relações entre educação, trabalho e emprego revestem-se de uma complexidade assinalável, para a qual tanto as dinâmicas macroeconómicas que afetam o mercado de trabalho como os fatores pessoais e sociais, entre os quais se incluem os que se associam à variável sexo, contribuem de forma significativa (Alves, 2007). 
Anexo I Universo, amostra, taxa de resposta e margem de erro amostral para as inquirições do OBIPNOVA a licenciados e mestres da NOVA entre 2010 e 2015

\begin{tabular}{l|r|rrrrrr}
\hline \multicolumn{2}{c|}{} & \multicolumn{7}{c}{ Ano } \\
\cline { 3 - 8 } \multicolumn{2}{c|}{} & 2010 & 2011 & 2012 & 2013 & 2014 & 2015 \\
\hline \multirow{2}{*}{ Licenciados } & Universo (N) & 1295 & 1112 & 1287 & 1330 & 1484 & 1282 \\
& Amostra (n) & 874 & 769 & 880 & 909 & 1027 & 724 \\
& Taxa de resposta (\%) & 67,4 & 69,2 & 68,4 & 68,3 & 68,4 & 56,5 \\
& Margem de erro (\%) & 1,9 & 2,0 & 1,9 & 1,8 & 1,7 & 2,4 \\
\hline Mestres & Universo (N) & 1432 & 1375 & 1664 & 1846 & 1820 & 1620 \\
& Amostra (n) & 1060 & 959 & 1131 & 1220 & 1200 & 844 \\
& Taxa de resposta (\%) & 74,0 & 69,7 & 68,0 & 66,1 & 65,9 & 52,1 \\
& Margem de erro (\%) & 1,5 & 1,7 & 1,6 & 1,6 & 1,7 & 2,3 \\
\hline
\end{tabular}

* Para um intervalo de confiança de $95 \%$ e assumindo a hipótese pessimista $[1,96 * \sqrt{ }(1-n / N) *(0,25 / n)]$. Fonte: OBIPNOVA. 


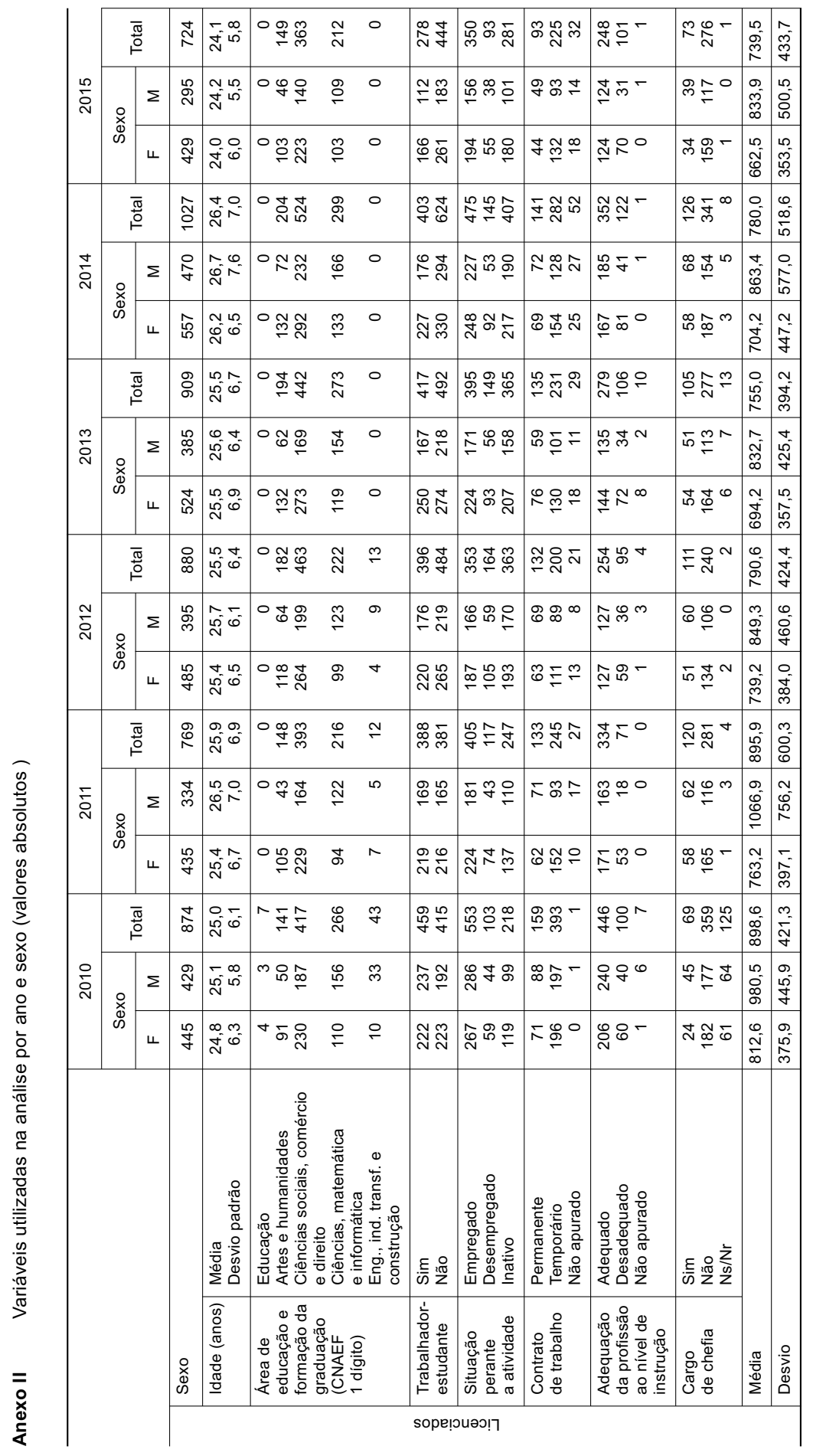




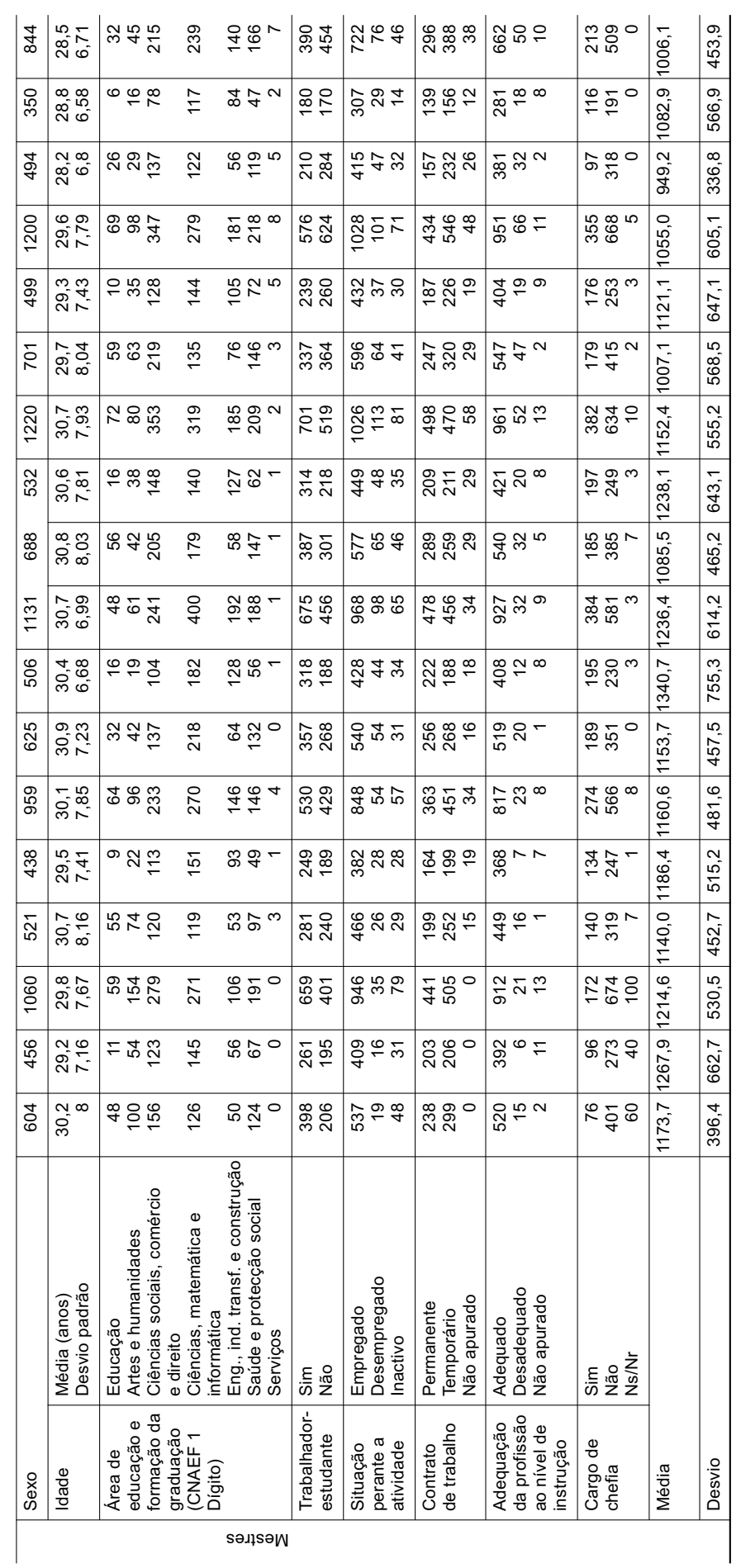




\section{Referências bibliográficas}

Acker, Joan (2009), “From glass ceiling to inequality regimes", Sociologie du Travail, 51, pp. 159-217.

Allen, Jim, e Rolf van der Velden (2007), The Flexible Professional in the Knowledge Society, Maastricht, RCELM.

Alves, Mariana Gaio (2004), “Os diplomados do ensino superior: diferenciação sexual nos processos de inserção profissional", Sociologia, 14, pp. 227-251.

Alves, Mariana Gaio (2007), A Inserção Profissional de Diplomados do Ensino Superior Numa Perspectiva Educativa. O Caso da Faculdade de Ciências e Tecnologia, Lisboa, Fundação Calouste Gulbenkian.

Alves, Mariana Gaio (2016), “O regresso de licenciados ao ensino superior: entre a inserção profissional e a educação ao longo da vida", Revista Brasileira de Educação, 21 (64), pp. 101-120.

Alves, Mariana Gaio, Natália Alves, e Miguel Chaves (2012), “Inserção profissional e razões de ingresso e reingresso no ensino superior", Sociologia, Problemas e Práticas, 69, pp. 99-118

Alves, Mariana Gaio, César Morais, e Miguel Chaves (2017), “Employability of higher education graduates in Portugal: trends and challenges in the beginning of the 21st century", Forum Sociológico, 31, pp. 9-19.

Alves, Natália (2009), Inserção Profissional e Formas Identitárias, Lisboa, Educa.

Cabrito, Belmiro, (1999), Análise Socioeconómica do Financiamento do Ensino Superior Universitário em Portugal. Contributos para o Processo Decisional de (re)Construção de Uma Política Socioeducativa para o Ensino Superior Universitário Público, Lisboa, Faculdade de Psicologia e Ciências da Educação da Universidade de Lisboa, tese de doutoramento.

Cardoso, José, et al. (2012), Empregabilidade e Ensino Superior em Portugal, Lisboa, A3ES.

Casaca, Sara (2012), “Mercado de trabalho, flexibilidade e relações de género: tendências recentes", em Sara Casaca (org.), Mudanças Laborais e Relações de Género. Novos Vetores de Desigualdade, Lisboa, Fundação Económicas / Almedina, pp. 9-50.

Chaves, Miguel, e César Morais (2014), “Nivelação e desigualdade na inserção profissional de diplomados do ensino superior", Sociologia, Problemas e Práticas, 76, pp. 87-108.

Comissão Europeia (2016), Employment and Social Developments in Europe, 2016, Luxemburgo, Comissão Europeia.

Costa, Ana, e José Caldas (2013), “A UE e Portugal entre os resgates bancários e a austeridade", em Observatório das Crises e das Alternativas, A Anatomia da Crise, Lisboa, Observatório das Crises e das Alternativas, pp. 72-107.

Doray, Pierre, e Christian Maroy (1995), “Les relations éducation-travail: quelques balises dans un océan conceptuel”, Revue des Sciences de l'Education, 21 (4), pp. 661-688.

Eurostat (2016), “Gender pay gap statistics (March 2017)”, consultado a 10/09/2017 em: http://ec.europa.eu/eurostat/statistics-explained/index.php/Gender_pay_gap_statistics

Ferreira, Virgínia (2010), “A evolução das desigualdades entre salários masculinos e femininos: um percurso irregular", em Virgínia Ferreira (org.), A Igualdade de Mulheres e Homens no Trabalho e no Emprego em Portugal. Políticas e Circunstâncias, Lisboa, CITE, pp. 139-190. 
Ferreira, Virgínia (2014), “Employment and austerity: changing welfare and gender regimes in Portugal", em Maria Karamessini e Jill Rubery (orgs.), Women and Austerity. The Economic Crisis and the Future of Gender Equality, Londres, Routledge, pp. 207-227.

Gonçalves, Carlos (2013), "Jovens e desemprego", em Ana Maria Brandão e Ana Paula Marques (orgs.), Jovens, Trabalho e Cidadania. Que Sentido(s), Braga, CICS, pp. 8-20.

Leathwood, Carol, e Becky Francis (orgs.) (2006), Gender and Lifelong Learning. Critical Feminist Engagements, Nova Iorque, Routledge.

Marques, Ana Paula, e Mariana Gaio Alves (orgs.) (2010), Inserção Profissional de Graduados em Portugal - (re)Configurações Teóricas e Empíricas, Braga, Edições Húmus.

McGuinness, Seamus (2006), “Overeducation in the labour market”, Journal of Economic Surveys, 20 (3), pp. 387-418.

Monteiro, Sílvio, Leadro Almeida, e Adela Aracil (2016), “Graduates' perceptions of competencies and preparation for labour market transition: the effect of gender and work experience during higher education", Higher Education, Skills and Work-Based Learning, 6 (2), pp. 208-220.

Navarro-Cendejas, José, e Jordi Planas Coll (2016), “Quelle influence du travail en cours d'études sur l'insertion professionnelle de diplômés universitaires catalans?", Formation et Emploi, 134 (2), pp. 47-65.

OECD (2016), Education at a Glance 2016, Paris, OECD Publishing.

Perista, Heloísa, Ana Cardoso, Ana Brázia, Manuel Abrantes, e Pedro Perista (2016), Os Usos do Tempo de Homens e de Mulheres em Portugal, Lisboa, CITE.

Rademacher, Walter, e Martin Leitner (2009), Bologna Process in Higher Education in Europe, Luxemburgo, European Comission.

Raffe, David (2014), “Explaining national differences in education-work transitions: twenty years of research on transition systems", European Societies, 16 (2), pp. 175-193.

Ramos, Madalena, Cristina Parente, e Mónica Santos (2014), “Os licenciados em Portugal: uma tipificação de perfis de inserção profissional", Educação e Pesquisa, 40 (2), pp. 383-400.

Robert, Peter, e Elu Saar (2012), "Learning and working: the impact of the 'double status position' on the labour market entry process of graduates in CEE countries", European Sociological Review, 28 (6), pp. 742-754.

Rostan, Michele, e Adriana Stan (2017), “Italian graduates' employability in times of economic crisis: overview, problems and possible solutions", Forum Sociológico, 2 (31), pp. 37-52.

Santos, Gina (2010), “Gestão, trabalho e relações sociais de género”, em Virgínia Ferreira (org.), A Igualdade de Mulheres e Homens no Trabalho e no Emprego em Portugal: Políticas e Circunstâncias, Lisboa, CITE, pp. 99-138.

Smyth, Emer (2003), “Gender differentiation and early labour market integration across Europe", em Irena Kogan e Walter Muller (orgs.), School-to-Work Transitions in Europe, Manheim, Universitat Manheim, pp. 55-88.

Sin, Cristina, Orlando, Tavares e Alberto Amaral (2016), "Student perceptions of the employability of the first degree in Portugal", Education + Training, 58 (9), pp. 966-983. 
Themelis, Spyros (2017), “Degrees of precariousness: the problematic transition into the labour market of Greek higher education graduates", Forum Sociológico, 2 (31), pp. 53-62.

Tomlinson, Michael (2008), “The degree is not enough: students' perceptions of the role of higher education credentials for graduate work and employability", British Journal of Sociology of Education, 29 (1), pp. 49-61.

Torres, Anália (2009), “Women, gender, and work: the Portuguese case in the context of the European Union", International Journal of Sociology, 38 (4), pp. 36-56.

Torres, Anália (coord.) (2018), Igualdade de Género ao Longo da Vida, Lisboa, Edições Fundação Francisco Manuel dos Santos.

Valadas, Carla (2013), “Mudanças nas políticas: do (des)emprego à empregabilidade", Revista Crítica de Ciências Sociais, 102, pp. 89-110.

Vuorinen-Lampila, Päivi (2016), “Gender segregation in the employment of higher education graduates", Journal of Education and Work, 29 (3), pp. 284-308.

Walby, Sylvia (2009), "Gender and the financial crisis", Paper for UNESCO Project on Gender and the Financial Crisis - Lancaster University, 1, pp. 1-33.

Mariana Gaio Alves. Professora auxiliar com agregação, UIDEF, Instituto de Educação, Universidade de Lisboa. E-mail: mga@ie.ulisboa.pt

César Morais. Professor assistente convidado, CICS.NOVA, Faculdade de Ciências Sociais e Humanas, Universidade Nova de Lisboa. E-mail: calm@fcsh.unl.pt

Receção: 28 de novembro de 2018 Aprovação: 24 de março de 2019 